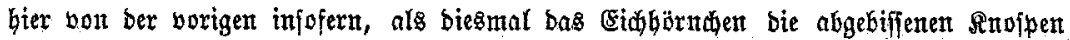
niajt fofort berzehrte, fonbern 4-5 Rnofpen - fobiele eben momentan erreidbar - im Malf famntelte, mit biejett auf eine benabjente Erle fprang und bort feinen Maub in

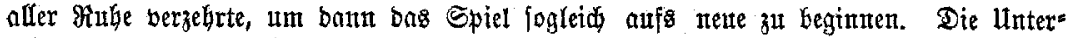
juctung bes bolftätbig gefitllten Magens exgab auper einigen unbebeutenbent braunen

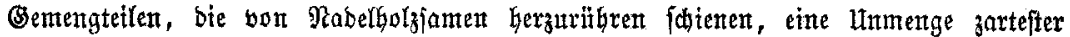
Iriebipisen; anfdeinent befantben fid baranter and Snofpen ber Tanne.

\title{
Groḱpe Pappel.
}

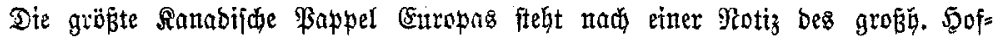

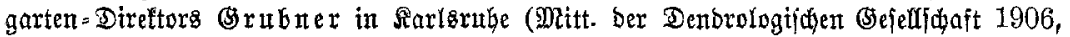

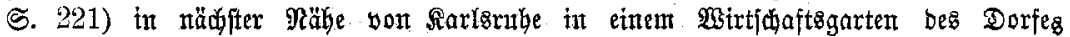
Beiersfeim. Ber nod volfftändig gefunbe Baum ift $38 \mathrm{~m}$ hod, hat am Boben einen Itmfang bont $11,35 \mathrm{~m}$, in $1 \mathrm{~m}$ föbe son $7 \mathrm{~m}$, ift gerabe, auf $10 \mathrm{~m}$ Łod aftreit, bidit

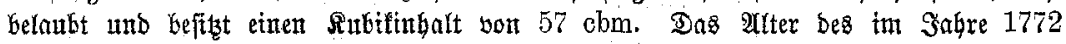
gepflantzten Baumes beträgt 134 Sahre.

Befonntlit ift bie Ranabijde Pappel jete Pappelart, weldje neurerbing unter alfen Pappelarten am meiften zum 2 nbau empfoblen wirb, eine Smpfeflung, bie obtger Bautm in hobem (srab fu reditfertigett fateint.

\section{Gauptoerfammlung des Deutfhen forftwereins.}

Die biegjährige Sauptverfammlung bes Dentiden Forjtereing finbet in ben

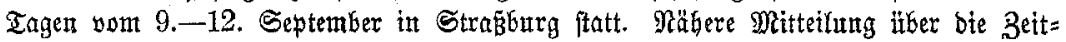

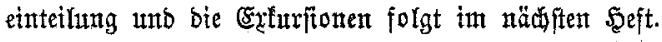

\section{Unterriḑtsfttpendient für förfterföhne.}

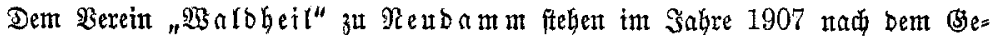

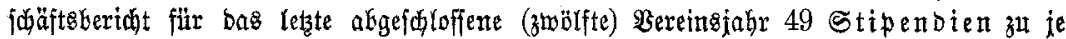

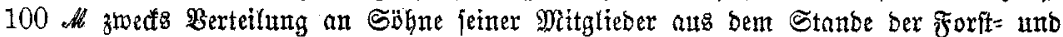
Sagbbeanten zur Berfïgung. Daton jollent fallen 27 an Sobne von Fribaiforftbeamten, 18 an Söhne von Stanteforftbeamten unb 4 an Söhne von Semeindeforftbeamtent.

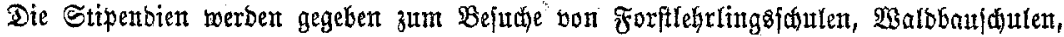
jowie and von böberen forftyiden Sebranftertent.

Inträge auf Bewitligung eines Stipentiumz fint von ben gefetzicionen Bertretern

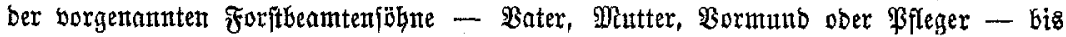

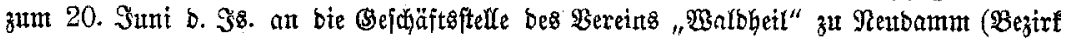
Franffurt $\mathfrak{a}$. D.) einzureiden. 